Article

\title{
Implication of Lactucopicrin in Autophagy, Cell Cycle Arrest and Oxidative Stress to Inhibit U87Mg Glioblastoma Cell Growth
}

\author{
Rossella Rotondo ${ }^{1}$, Maria Antonietta Oliva ${ }^{2}$, Sabrina Staffieri ${ }^{2}$, Salvatore Castaldo ${ }^{2}$, \\ Felice Giangaspero ${ }^{2,3}$ and Antonietta Arcella 2,*(D) \\ 1 Department of Molecular Medicine and Medical Biotechnologies, University of Naples Federico II, \\ 80131 Naples, Italy; rossellaross1988@gmail.com \\ 2 I.R.C.C.S Neuromed, Via Atinense, 18, 86077 Pozzilli IS, Italy; mariaantonietta.oliva@neuromed.it (M.A.O.); \\ sabrina.staffieri@neuromed.it (S.S.); castaldosal90@gmail.com (S.C.); felice.giangaspero@uniroma1.it (F.G.) \\ 3 Department of Radiologic, Oncologic and Anatomo Pathological Sciences, University of Rome La Sapienza, \\ 00185 Rome, Italy \\ * Correspondence: arcella@neuromed.it; Tel.: +39-0865-915220
}

Academic Editor: José Antonio Lupiáñez

Received: 19 November 2020; Accepted: 8 December 2020; Published: 10 December 2020

check for updates

\begin{abstract}
In this study, we propose lactucopicrin (LCTP), a natural sesquiterpene lactone from Lactucavirosa, as a molecule able to control the growth of glioblastoma continuous cell line U87Mg. The IC50 of U87Mg against LCTP revealed a strong cytotoxic effect. Daily administration of LCTP showed a dose and time-dependent reduction of GBM cell growth and viability, also confirmed by inhibition of clonogenic potential and mobility of U87Mg cells. LCTP activated autophagy in U87Mg cells and decreased the phosphorylation of proliferative signals pAKT and pERK. LCTP also induced the cell cycle arrest in G2/M phase, confirmed by decrease of CDK2 protein and increase of p53 and p21. LCTP stimulated apoptosis as evidenced by reduction of procaspase 6 and the increase of the cleaved/full-length PARP ratio. The pre-treatment of U87Mg cells with ROS scavenger $\mathrm{N}$-acetylcysteine (NAC), which reversed its cytotoxic effect, showed the involvement of LCTP in oxidative stress. Finally, LCTP strongly enhanced the sensitivity of U87Mg cells to canonical therapy Temozolomide (TMZ) and synergized with this drug. Altogether, the growth inhibition of U87Mg GBM cells induced by LCTP is the result of several synergic mechanisms, which makes LCTP a promising adjuvant therapy for this complex pathology.
\end{abstract}

Keywords: glioblastoma (GBM); lactucopicrin (LCTP); temozolomide (TMZ); autophagy; oxidative stress; NF-kB; p62/SQSM1

\section{Introduction}

Glioblastoma (GBM) is one of the most lethal brain tumors in adults, with survival rates which have remained substantially unchanged for 30 years. Common histological features of GBM comprise marked mitotic activity, high angiogenesis, cellular heterogeneity, necrosis, and pronounced proliferative rates [1]. Furthermore, the presence of cancer stem cells, able to proliferate and generate glial neoplastic cells [2,3], contributes to the unfavorable prognosis of GBM patients, whose median survival is approximately 14 months [4]. Gross-total resection of tumor tissue, followed by adjuvant chemoand radiotherapy, remains the standard of care [5]. Numerous efforts have been made to identify the molecular pathways and potential "druggable" targets involved in gliomagenesis [6].

Temozolomide (TMZ) is a first-line chemotherapy that has significantly improved the prognosis of GBM patients [7]. However, development of TMZ resistance in some GBM patients during the 
therapeutic program limits the treatment of this brain tumor. The main mechanism of GBM resistance involves O6-methylguanine-DNA methyltransferase (MGMT) enzyme repair. MGMT acts by removing the methyl group attached to the $\mathrm{O} 6$ position in guanine from DNA of cancer cells, favoring a resistant phenotype [8]. However, other mechanisms contribute significantly to TMZ resistance [9]. Several molecules have been developed to overcome TMZ resistance, such as O6-benzyl-guanine which inhibits MGMT, tyrosine kinase inhibitors which modulate the epidermal growth factor receptor (EGFR) commonly overexpressed in GBMs, and nutlin-3 which inhibits murine double minute 2 (Mdm2), that in turn leads to restoration of p53 activity.

Due to the failure of classical chemotherapies and targeted drugs, research efforts are focusing on natural compounds that can overcome BBB, inhibit tumor growth and are able to promote the activity involving multiple pathways [10]. In fact, since multiple pathways are associated with TMZ resistance in GBM [11], the treatment of GMB with a selective target drug that blocks the activation of a single pathway could result in a compensatory mechanism that leads to the restoration of signals, conferring a TMZ resistance [12]. Interestingly, multiple natural compounds have already shown antitumor and apoptotic effects in TMZ resistant GBM cell lines and also displayed synergistic affects with TMZ $[10,13,14]$. Sesquiterpene lactones are a large and different group of biologically active plant compounds with anti-inflammatory and anti-tumor activity. Sesquiterpene lactones are secondary metabolites of the Asteraceae family, which exhibits great structural diversity and a broad range of biological activities $[15,16]$. As a member of the sesquiterpene superfamily, they are composed by 15-carbon skeletons, consisting of colorless, crisp and dry lipophilic compounds made up of three isopropyl units $[17,18]$. The biological activities of sesquiterpene lactones are due to the presence of $\alpha$-methylene- $\gamma$-lactone, which reacts with nucleophilic structure of multiple targets through Michael's reaction, such as the thiol group of cysteinyl residues [17]. Therefore, they can exert their effects through the alkylation of transcription factors and various enzymes, interfering with several molecular pathways [19]. In the last few years, extensive research has confirmed the anticancer activity of different compounds within the sesquiterpene lactones and much effort has been undertaken to clarify the molecular mechanism and chemotherapeutic potential of some of these compounds in GMB treatment [20-22]. Very recently, Zhang et al. reported that lactucopicrin (or intybin), a secondary metabolite of lactucarium, derived from the plant Lactuca virosa (wild lettuce) and found in some related plants, such as Cichorium intybus, exhibits its anticancer activity in SKMEL-5 human skin cancer cells [23] and growth inhibition of Saos-2 osteosarcoma cells [24].

For a long time, lactucarium, a milky and bitter juice secreted by stem secretion of these plants, once dried, has been used as an opium substitute for its analgesic and sedative properties. Therefore, considering the ability of lactucopicrin to act on central nervous system, it can be speculated that this molecule can cross the BBB acting as multi-target molecule, potentially interfering with GMB cell growth. Therefore, we studied the effect of this natural substance to exploit the novel vulnerabilities of human glioblastoma cell line U87Mg.

\section{Results}

\subsection{Dose-Response and Time-Course of LCTP Effects on Glioblastoma U87Mg Cells}

The cytotoxic effects of LCTP on glioblastoma were investigated using continuous glioblastoma cell line U87Mg and estimating the IC50 of LCTP at 24, 48, and $72 \mathrm{~h}$. As it is evident in Figure 1B, the IC50 of LCTP against U87Mg cells decreased from $12.5 \pm 1.1 \mu \mathrm{M}(5.1 \pm 0.5 \mu \mathrm{g} / \mathrm{mL})$ at $24 \mathrm{~h}$ to $3.6 \pm 1.1 \mu \mathrm{M}(1.5 \pm 0.5 \mu \mathrm{g} / \mathrm{mL})$ at $72 \mathrm{~h}$. Considering the strong cytotoxicity of this molecule, LCTP was daily administered at concentrations of 7.5 and $10 \mu \mathrm{M}$ at various time intervals (24, 48 and $72 \mathrm{~h}$ ). We found that LCTP exhibited a statistically significant time- and dose-dependent growth inhibition of U87Mg, as measured by direct cell count (Figure 1D), which resulted in a growth rate inhibition that increased from $60 \%$ and $82 \%$ at $48 \mathrm{~h}$, respectively, with LCTP 7.5 and $10 \mu \mathrm{M}$ to $85 \%$ and $94 \%$ of inhibition at $72 \mathrm{~h}$ of treatment. Cell viability assay and morphological changes were also reported 
in Figure 1C,E. According to the growth rate inhibition, LCTP inhibited the viability of U87Mg in a time and dose-dependent manner, with about $50 \%$ of reduction at $72 \mathrm{~h}$ of treatment with LCTP $10 \mu \mathrm{M}$. LCTP induced dramatic morphological changes of U87Mg, visible at microscopically observation as rounded-shaped with a loss of filaments and cell shrinkage (Figure 1C).

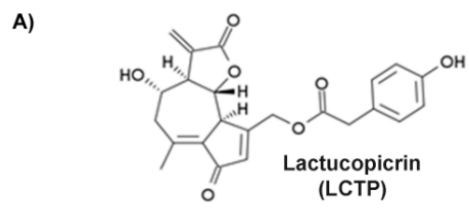

C)

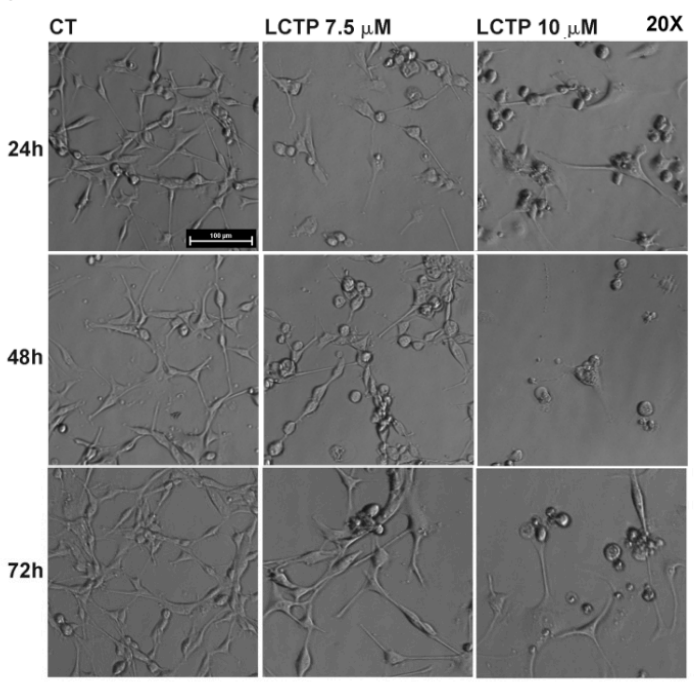

F)

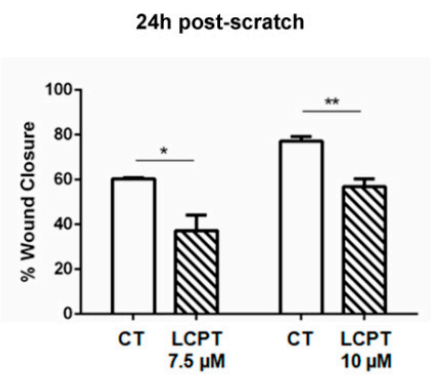

B)

\begin{tabular}{ccc}
\hline \multicolumn{3}{c}{ IC $50(\mu \mathrm{M})$ LCTP } \\
\hline $24 \mathrm{~h}$ & $48 \mathrm{~h}$ & $\mathbf{7 2 h}$ \\
\hline $12.5 \pm 1.1$ & $8.2 \pm 1.0$ & $3.6 \pm 1.1$ \\
\hline
\end{tabular}

D)

E)
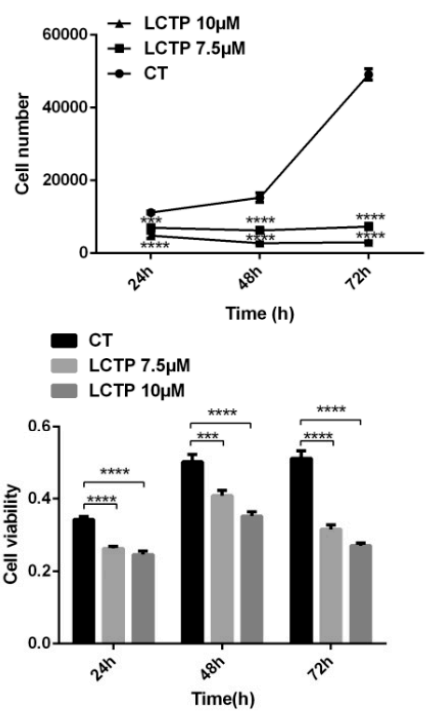

G)

CT

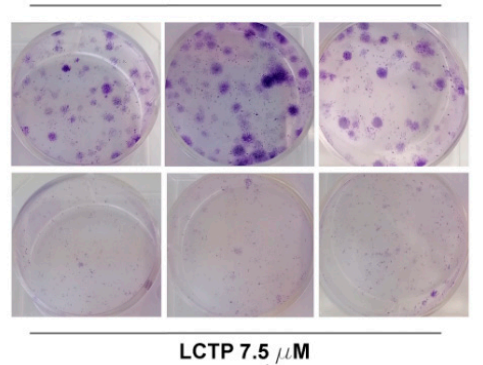

Figure 1. (A) Chemical structure of LCTP. (B) IC50-values of U87Mg cells after 24,48 and $72 \mathrm{~h}$ of incubation with LCTP. (C) Morphological changes of U87Mg glioblastoma cells treated every $24 \mathrm{~h}$ with LCTP 7.5 and $10 \mu \mathrm{M}$ for 24, 48 and $72 \mathrm{~h}$. Magnification 20x. (D) Time and dose-dependent growth inhibition of LCTP-treated U87Mg cells. (E) Cytotoxic effect of various concentrations of LCTP (7.5 and $10 \mu \mathrm{M}$ ) at 24, 48 and $72 \mathrm{~h}$ post-treatment on U87Mg cell line. (F) Quantification of the cell-free area in wound healing assay at T0 and $24 \mathrm{~h}$ post-scratch in control and LCTP-treated U87Mg cells. (G) Colony-forming assay of U87Mg treated $24 \mathrm{~h}$ with LCTP 7.5. $\mu \mathrm{M}$. For all the experiments, values are the means \pm SEM of 3 individual determinations. Unpaired $t$-test, $p$-value $<0.05$. According to GraphPad Prism, * $p$-value 0.01 to 0.05 (significant), ${ }^{* *} p$-value 0.001 to 0.01 (very significant), ${ }^{* * *} p$-value 0.0001 to 0.001 (Extremely significant), ${ }^{* * *} p$-value $<0.0001$ (Extremely significant).

\subsection{LCTP Interferes with Clonogenic Survival and Motility Capacity of GBM Cells}

To further investigate the growth inhibition effects of LCTP, a colony assay of U87Mg treated with LCTP and control vehicle (DMSO) was performed. LCTP dramatically reduced the colony forming of U87Mg; at the lowest concentration used $(7.5 \mu \mathrm{M})$, this natural molecule completely suppressed clonogenic growth (Figure $1 \mathrm{G}$ ). LCTP also affected the cell motility of U87Mg, as it was 
demonstrated by the wound healing assay. The plot in Figure $1 \mathrm{~F}$ showed that the percentage of wound closure significantly decreased with the increase of LCTP concentrations at $24 \mathrm{~h}$ post-scratch (Supplementary Figure S1).

\subsection{Rapid Autophagy Response of U87Mg to LCTP Treatment Potentially Remodels the Cytoskeleton Proteins}

The molecular mechanisms underlying LCTP-induced cytotoxicity were investigated exposing U87Mg cells to short-term treatment with LCTP $10 \mu \mathrm{M}$. In the Western blot analysis, in Figure 2A, the strong reduction of autophagic substrate p62/SQSM1 appears evident, already being visible after 30 min of induction followed by the increased of cleaved LC3BII, clearly indicating the activation of autophagy in GBM cells treated with LCTP, with respect to control cells. Autophagy activation may be sustained by a deep dephosphorylation of ${ }^{S e r 473} \mathrm{pAKT}$ and $\mathrm{pERK} 1 / 2$ proteins in a LCTP-short-term treatment of U87Mg cells (Figure 2B). Interestingly, LCTP induced a strong cytoskeleton rearrangement in U87Mg cells, as it can be appreciated by immunofluorescence staining for intermediated filament Vimentin and the $\alpha$-tubulin subunit of microtubules (Figure 2C).

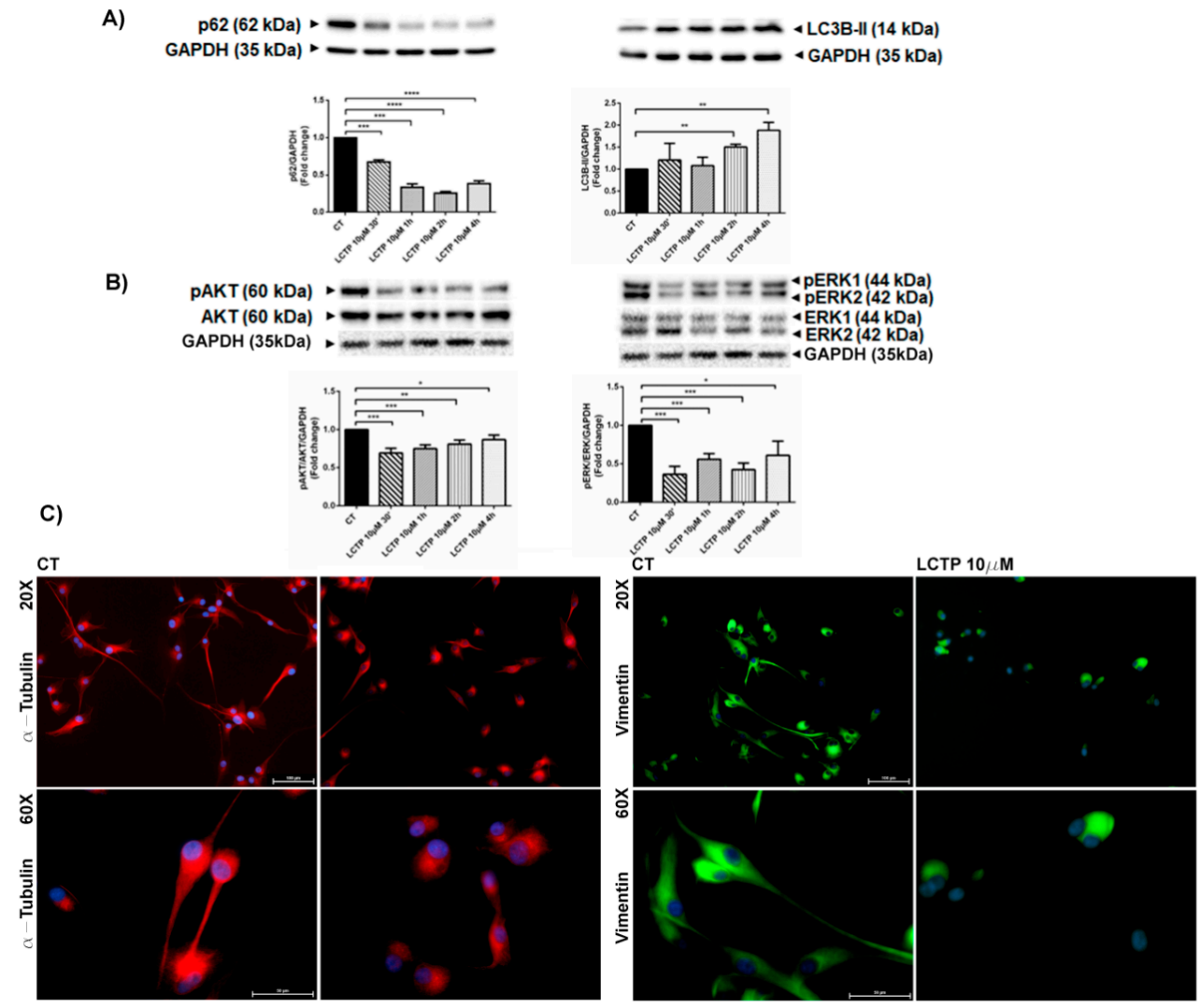

Figure 2. (A) Western blot analysis of autophagy-associated proteins p62 and LC3BII in short-termtreatedU87Mg cells with LCTP $10 \mu \mathrm{M}$. Densitometric analysis of protein levels represent the means \pm SEM of 3 individual determinations. Data were normalized to GAPDH and are expressed as fold change over control-treated cells. ${ }^{*}$ Unpaired $t$-test, $p$-value $<0.05$. (B) Western blot analysis of proliferative signals $\mathrm{pERK} / \mathrm{ERK} / \mathrm{GAPDH}$ and $\mathrm{pAKT} / \mathrm{AKT} / \mathrm{GAPDH}$ in short-termtreated-U87Mg cells with LCTP $10 \mu \mathrm{M}$. Densitometric analysis of protein levels represent the means \pm SEM of 3 individual determinations and are expressed as fold change over control-treated cells, normalized to GAPDH. * Unpaired $t$-test, $p$-value $<0.05$. According to GraphPad Prism, ${ }^{*} p$-value 0.01 to 0.05 (significant), ${ }^{* *} p$-value 0.001 to 0.01 (very significant), ${ }^{* * *} p$-value 0.0001 to 0.001 (Extremely significant), ${ }^{* * * *} p$-value $<0.0001$ (Extremely significant). (C) Immunofluorescence analysis of cytoskeleton proteins $\alpha$-tubulin and Vimentin in U87Mgcells treated with LCTP $10 \mu \mathrm{M}$ and vehicle control (DMSO 0.08\%) for $20 \mathrm{~min}$. Magnification 20x and $60 \times$. 


\subsection{Cell Cycle Arrest in G2/M Phase and Apoptosis Induction by LCTP in U87Mg Cells}

To clarify the mechanism that regulates GBM cell growth inhibition, the long-term effects of LCTP on cell cycle distribution were investigated by flow cytometry. The analysis revealed that the cell cycle arrest in G2/M phase in LCTP-induced U87Mg cells was already visible at 24 h post-treatment (Figure 3A). The cell cycle distribution showed that the arrest in the G2/M phase-and concomitant decrease of cell percentage at the G0/G1 phase - is time-dependent (Figure 3B). In order to clarify the molecular mechanism underlying the growth inhibition of the U87Mg cells, the expression levels of key proteins which regulate the cell cycle were determined by Western blot analysis. As shown in Figure 3C, the long-term treatment of U87Mg cells with LCTP $7.5 \mu \mathrm{M}$ induced the activation of CDK inhibitor p21, which was already up-regulated after $24 \mathrm{~h}$ of treatment. The tumor suppressor p53 was strongly activated at $72 \mathrm{~h}$ post-treatment in accordance, with the pronounced accumulation of cell population in the G2/M phase at the same time point (Figure 3B,C). The up-regulation of p21 and p53, after $72 \mathrm{~h}$, is correlated to CDK2 inhibition in LCTP-treated cells, confirming the cytostatic activity of LCTP in U87Mg cells (Figure 3D). In the same conditions, to further investigate whether the anti-proliferative effect of LCTP was accompanied by the induction of cell death, Western blot analysis of apoptotic proteins was performed. In U87Mg-treated cells at 48 and $72 \mathrm{~h}$ post-treatment, procaspase 6 decreased, while cleaved/full-length ratio of Poly(ADP)ribose polymerase (PARP) significantly increased, clearly indicating the activation of programmed cell death by LCTP (Figure 3E,F). Loss of repair activity of cleaved PARP was also confirmed by the appearance of DNA fragments, as shown on $2 \%$ agarose gel electrophoresis at $72 \mathrm{~h}$ of LCTP-treatment (Figure 3G).

\subsection{Involvement of Oxidative Stress in LCTP-Mediated Cytotoxicity in U87Mg Cells}

The involvement of oxidative stress in LCTP-induced cytotoxicity is due to the presence of highly reactive $\alpha$-methylene- $\gamma$-lactone group. This group is able to react with nucleophilic structure of multiple targets through Michael's reaction, such as the thiol group of cysteinyl residues [17]. The oxidative stress LCTP-induced cytotoxicity was demonstrated by pre-incubating U87Mg with $\mathrm{N}$-acetylcysteine. Pre-treatment with ROS scavenger NAC reverted the LCTP effects on U87Mg cell viability and preserved cell morphology (Figure 4A,B). These results suggest that LCTP induces a redox imbalance that potentially mediates its anti-proliferative activity. ROS can influence tumor cell malignancy via the redox-regulated transcription factor NF- $\mathrm{KB}$ [25]. Therefore, Western blot analysis of short-term LCTP-treated GBM cells was performed to assess the expression levels of NF- $\mathrm{B}$ p65 subunit. The down-regulation of NF-kB p65 expression upon LCTP treatment was already visible after 30 min of incubation with the drug and persisted throughout all of the time tested ( $1 \mathrm{~h}, 2 \mathrm{~h}$, and $4 \mathrm{~h}$ ) (Figure $4 \mathrm{C}$ ). The expression of NF-кb p65 at long-term treatment was also tested (Supplementary Figure S2).

\subsection{LCTP Enhances the Sensitivity of U87Mg to Canonical Therapy Temozolomide}

To assess whether the effects of LCTP can influence the response to TMZ, U87Mg cells were pre-treated with LCTP $7.5 \mu \mathrm{M}$ and $10 \mu \mathrm{M}$ for $24 \mathrm{~h}$ and IC50 for TMZ at $24 \mathrm{~h}$, which was determined to be compared with the standard IC50. As shown in Figure 5A,B, the IC50 of TMZ at 24 h was about 18 and 32 times higher compared to IC50 for TMZ at $24 \mathrm{~h}$ when U87Mg cells were pre-treated with LCTP $(7.5 \mu \mathrm{M}$ and $10 \mu \mathrm{M})$. It is worth noting that the lower IC50 of U87Mg to LCTP if compared with TMZ at 24 and $48 \mathrm{~h}$, indicating a strong effect of LCTP in a short-term period, which could explain the rapid activation of autophagic pathway. At $72 \mathrm{~h}$, the IC50 for TMZ and LCTP of U87Mg cells became comparable (Figures 1B and 5A). 
A) CT LCTP $7.5 \mu \mathrm{M}$

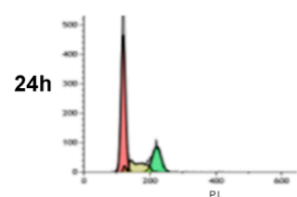

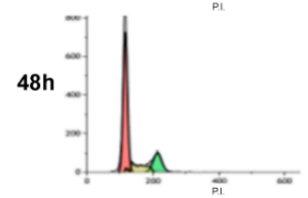
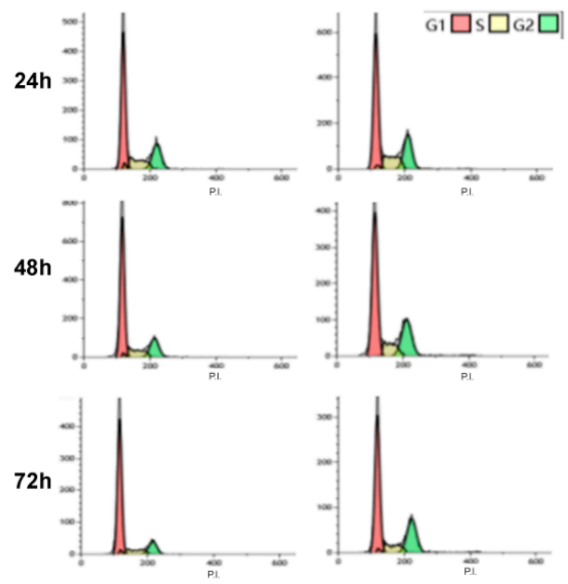

C)

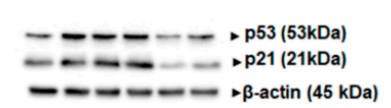

B) 口 G0/G1 صS G2/M

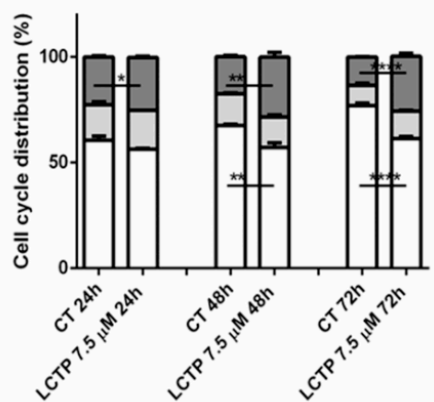

D)

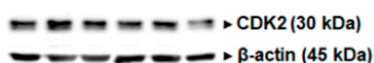

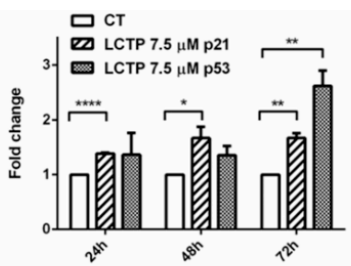

E)

ニニニニニニーP Procaspase 6( kDa)

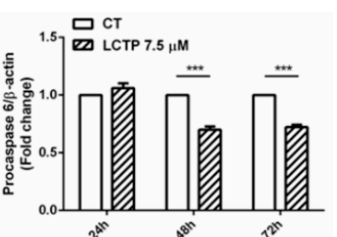

F)

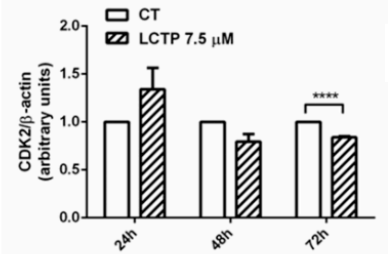
Full lenght PARP (116 kDa)
Cleaved PRPP (89 kDa)
$\beta-$ actin (45 kDa) G)
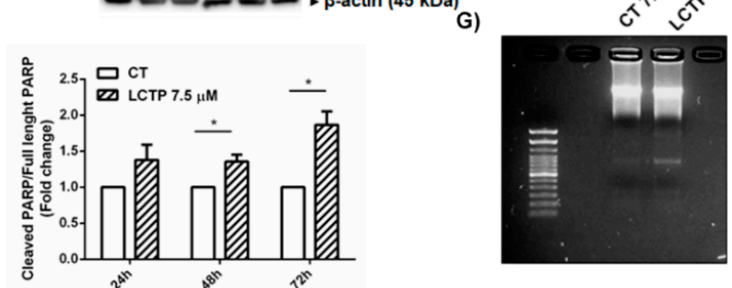

Figure 3. (A) Representative flow cytometry analysis of cell cycle arrest in G2/M and (B) plot of cell cycle distribution of propidium iodide (PI) staining in U87Mg, vehicle (left panel) and LCTP $(7.5 \mu \mathrm{M})$ treated cells (right panel) for 24,48 and $72 \mathrm{~h}$. Values are the means \pm SEM of 3 individual determinations. * Unpaired $t$-test, $p$-value $<0.05$. (C) Western blot analysis of p53 and p21 in long-term LCTP-treated U87Mg cells. Data were normalized to $\beta$-actin and are expressed as fold change over control-treated cells of 3 individual determinations. * Unpaired $t$-test, $p$-value $<0.05$. (D) Western blot analysis of CDK2: the figure shows CDK2 analysis of U87Mg cells treated with LCTP $7.5 \mu \mathrm{M}$ at different time $(24,48$, and $72 \mathrm{~h}$ ). Data were normalized to $\beta$-actin and are expressed as fold change over control-treated cells of 3 individual determinations. * Unpaired $t$-test, $p$-value $<0.05$. (E) Western blot and densitometric analysis of procaspase 6 of LCTP-treated U87Mg cells at different time $(24,48$ and $72 \mathrm{~h})$. Values are the means \pm SEM of 3 individual determinations and protein expression levels, normalized to $\beta$-actin, are expressed as fold change over control-treated cells. ${ }^{*}$ Unpaired $t$-test, $p$-value $<0.05$. (F) Western blot analysis of PARP in LCTP-treated U87Mg cells at different time (24, 48 and $72 \mathrm{~h})$. Values as ratio of cleaved PARP to full-length PARP represent the means \pm SEM of 3 individual determinations and are expressed as fold change over control-treated cells. * Unpaired $t$-test, $p$-value $<0.05$. According to GraphPad Prism, * $p$-value 0.01 to 0.05 (significant), ${ }^{* *} p$-value 0.001 to 0.01 (very significant), ${ }^{* * *} p$-value 0.0001 to 0.001 (Extremely significant), ${ }^{* * * *} p$-value $<0.0001$ (Extremely significant). (G) DNA laddering of long-term treatment of U87Mg cells with LCTP 7.5 with respect to untreated cells. 
A)

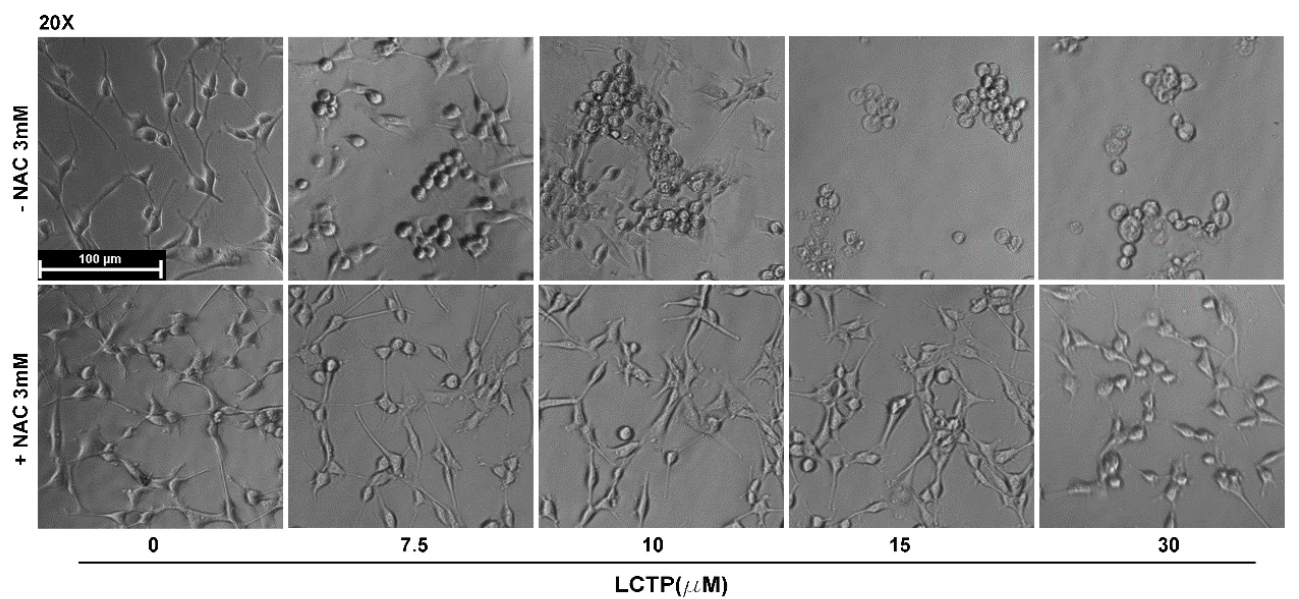

B)

$\square$ Cell viability (-NAC)
$\square$ Cell viability (+NAC)

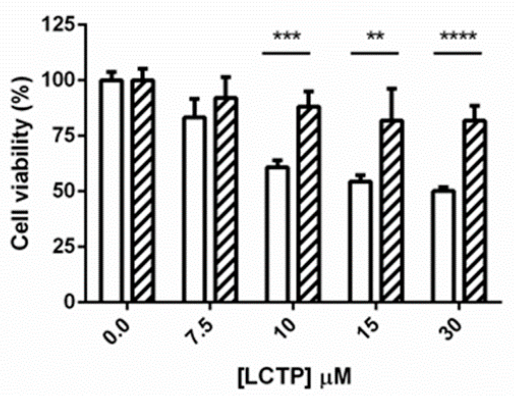

C)

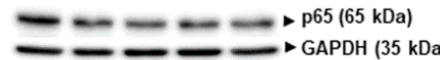

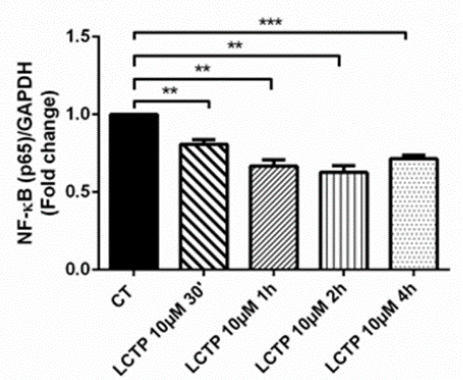

Figure 4. (A) Effect of pre-treatment with ROS scavenger NAC $3 \mathrm{mM}$ for $4 \mathrm{~h}$ on morphological changes and (B) cell viability (\%) induced by different concentrations of LCTP $(7.5,10,15$ and $30 \mu \mathrm{M})$ on U87Mg cells at $24 \mathrm{~h}$ from treatment. Magnification 20x. (C) Western blot analysis of NF-kB p65 subunit of short-term treated U87Mg cells with LCTP $7.5 \mu \mathrm{M}$ (30 min, $1 \mathrm{~h}, 2 \mathrm{~h}$ and $4 \mathrm{~h}$ ). Data were normalized to GAPDH and are expressed as fold change over control-treated cells of 3 individual determinations. According to GraphPad Prism, ${ }^{* *} p$-value 0.001 to 0.01 (very significant), ${ }^{* * *} p$-value 0.0001 to 0.001 (Extremely significant), ${ }^{* * *} p$-value $<0.0001$ (Extremely significant).

\subsection{Synergist Effect of LCTP and TMZ Affects the Cell Growth and Viability}

In order to propose LCTP as an adjuvant therapy for GBM, in combination with conventional chemotherapy TMZ, U87Mg cells were treated every $24 \mathrm{~h}$ with LCTP $7.5 \mu \mathrm{M}$ and $10 \mu \mathrm{M}$ in combination with TMZ $1 \mu \mathrm{M}$ for 24,48 . and $72 \mathrm{~h}$. The effects of the combined therapy were assessed on cell growth and viability. Concomitant treatment with the two drugs significantly increased the effect of TMZ alone, inhibiting the replicative potential of U87Mg cells already from $24 \mathrm{~h}$ post-treatment (Figure 5C,D). 
A)

\begin{tabular}{ccc}
\hline \multicolumn{3}{c}{ IC50 $(\mu \mathrm{M})$ TMZ } \\
\hline $24 \mathrm{~h}$ & $48 \mathrm{~h}$ & $\mathbf{7 2 h}$ \\
\hline $156.7 \pm 1.0$ & $134.3 \pm 1.1$ & $4.7 \pm 1.1$ \\
\hline
\end{tabular}

C)

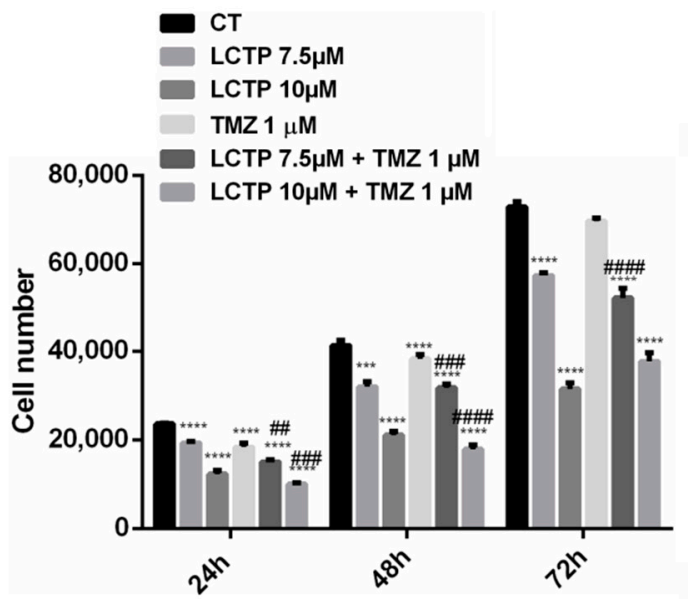

B)

\begin{tabular}{cc}
\hline LCTP-pretreatment $(\mu \mathrm{M})$ & $\mathrm{IC} 50(\mu \mathrm{M})$ TMZ24h \\
\hline- & $156.7 \pm 1.0$ \\
7.5 & $8.5 \pm 1.4$ \\
10 & $4.8 \pm 2.0$ \\
\hline
\end{tabular}

D)

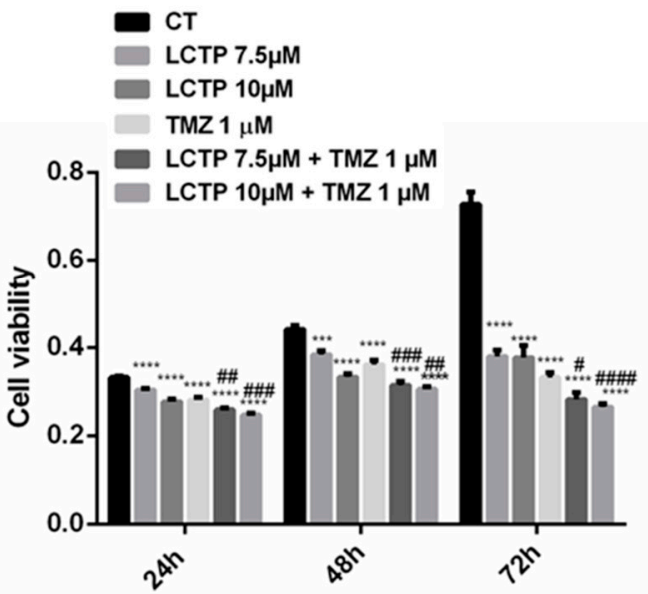

Figure 5. (A) IC50-values of U87Mg cells after 24, 48 and $72 \mathrm{~h}$ of incubation with TMZ. (B) IC50-values of TMZ at $24 \mathrm{~h}$ of U87Mg cells pre-treated with LCTP 7.5 and $10 \mu \mathrm{M}$ for $24 \mathrm{~h}$. (C) Synergistic effect of LCTP and conventional chemotherapy TMZ ongrowth of U87Mg cells. Values are the means \pm SEM of 3 individual determinations. \# $p$-value compared to cells treated with TMZ alone. (D) Synergistic effect of LCTP and conventional chemotherapy TMZ oncell viability of U87Mg cells. Values are the means \pm SEM of 3 individual determinations. \# $p$-value $<0.05$ compared to cells treated with TMZ alone. According to GraphPad Prism, \# p-value 0.01 to 0.05 (significant), \#\# p-value 0.001 to 0.01 (very significant), ${ }^{* * *}$ or \#\#\# $p$-value 0.0001 to 0.001 (Extremely significant), ${ }^{* * * *}$ or \#\#\# $p$-value $<0.0001$ (Extremely significant).

\section{Discussion}

The current oncology protocol for glioblastoma patients provides, after surgery, treatment with chemotherapeutic agents, such as TMZ, associated with radiotherapy (Stupp protocol) [5]. Over the past 10 years, however, therapeutic agents have not significantly increased the median survival rate of patients with glioblastoma. The 5-year survival rate for patients with the same disease, after treatment including surgical resection, radiotherapy, and chemotherapy, remains less than 9.8\% [26].

Therapeutic approaches used against glioblastoma are associated with the development of resistance and with important side effects, which can very often represent a real obstacle for the patient in completing chemotherapy, and this can lead to therapeutic failure. For this reason, the current research is moving towards using natural substances as adjuvants to a traditional therapy that can, on the one hand, have an antitumor action (synergistic with temozolomide) and, on the other, soothe the side effects. A large number of clinical studies have demonstrated the benefits derived from the use of herbal medicines in combination with conventional therapies on the survival, immune modulation, and quality of life of cancer patients [27]. Here, we examined the anti-proliferative effects of a natural compound, Lactucopicrin, commonly found in Lactuca virosa, on human glioblastoma cells U87Mg. The effects of LCTP on the proliferation of GBM continuous cell line U87Mg were evaluated by setting up growth curves. To study the effect of LCTP on the growth rate of human glioma cells U87Mg, we applied the drug at chosen concentration $(7.5$ and $10 \mu \mathrm{M})$ to the growing medium once daily for three days, starting one day after plating. These applications had already reduced the growth in culture after only $24 \mathrm{~h}$ post-treatment. A time- and dose-dependent growth rate inhibition was observed in 
U87Mg upon LCTP treatment. This trend was also confirmed by results obtained for cell viability assay. In accordance with results from cell count and MTT assay, the growth inhibitory effect of LCTP on U87Mg cell was also confirmed by clonogenic assay. In fact, at the lower concentration chosen $(7.5 \mu \mathrm{M})$, LCTP completely suppressed the potential clonogenicity of U87Mg cells. Migration is a peculiar aspect which favors the aggressiveness and poor prognosis glioblastoma [28]; in this regard, our results evidence a dose-dependent, anti-migratory effect of LCTP on U87Mg cells, since the ability of cells to close the scratch decreased with LCTP concentrations.

The half-maximal inhibitory concentration of LCTP against U87Mg was determined at different time points, revealing a strong cytotoxic effect of LCTP. The IC50 for LCTP in the micromolar range is in line with the previously reported data in human SKMEL-5 [23]. Interestingly, compared with conventional chemotherapy TMZ, the IC50 of LCTP at 24 and $48 \mathrm{~h}$ resulted in being more than 10 times lower, becoming comparable only at $72 \mathrm{~h}$ of treatment.

In order to evaluate the potential synergism of TMZ with LCTP, the preliminary ability of this natural molecule to arrest the cell proliferation of U87Mg cells was investigated by comparing the IC50-values for TMZ before and after treatment with LCTP. LCTP strongly increased the sensitivity of U87Mg to TMZ. Finally, to test the synergism with TMZ (canonical drug for GBM) and to propose LCTP as adjuvant therapy, the GBM cell growth and viability were analyzed upon combined treatment which demonstrated a synergistic effect. We considered that it would be interesting to investigate the mechanisms involved in inhibiting cell growth after LCTP administration. Since members of the sesquiterpene lactone family have been reported to induce $S$ and G2/M cell cycle arrest and cell death inducing apoptosis through PARP cleavage $[20,23,29]$, the ability of LCTP to induce the cell cycle arrest in GBM U87Mg cells was evaluated by flow cytometry analysis. The results demonstrated a block of the cell cycle in the G2/M phase, especially $72 \mathrm{~h}$ after treatment with LCTP. The cell cycle arrest was supported by the increased expression of the CDK inhibitor p21 and oncosuppressor p53, while CDK2 protein decreased. The cell cycle blockage is not to be considered as the only mechanism that determines the growth inhibition of U87Mg cells after treatment with LCTP. In this order, the molecular activation of the apoptotic and autophagic responses, as well as the key pathways of proliferation U87Mg continuous cell line, were assessed by Western blot analysis of GBM cell extracts after treatments. Long-term exposure to LCTP $7.5 \mu \mathrm{M}$ revealed an increase cleaved/full-length PARP ratio, confirming an involvement of the apoptotic pathway which is already visible by procaspase 6 decrease at 48 and $72 \mathrm{~h}$ of induction with LCTP.

The pro-apoptotic and cytostatic effects of LCTP may be the results of a rapid activation of autophagic pathway. The autophagy adaptor p62/SQSM1 has been reported to act as an oncogene in glioma and has been proposed as a novel therapeutic target for this pathology [30]. Moreover, a decreased expression of p62/SQSM1 induced a significant decrease of ERK phosphorylation [31]. According to previous literature, in our study, Western blot analysis revealed a strong and rapid reduction of p62/SQSM1 accompanied by the increase of cleaved LC3BII and a remarkable dephosphorylation of ERK1/2 kinases in LCTP-treated cells. The presence of $\alpha$-methylene- $\gamma$-lactone promotes the nucleophilic attack of sesquiterpene lactones to multiple targets through Michael's reaction, such as the redox regulator NF- $\mathrm{kB}$ [17]. The constitutive activation of this transcription factor has been shown to stimulate the growth and survival of GBM [32]. Several natural sesquiterpene lactones act as NF-kB inhibitors [33], such as parthenolide and artemisinin, which enhance the sensitivity of cancer cells to chemotherapy [34,35]. In this regard, the effect of LCTP on the NF-kB p65 subunit was investigated by Western blot analysis, that revealed a significant reduction of p65 expression levels already appreciable at $30 \mathrm{~min}$ from induction. According to Jing et al., the autophagic degradation of p62/SQSM1 can lead the inhibition of NF-kB pathway and thus inhibit the proliferation of U87Mg glioblastoma cells [36]. The high nucleophilic reactivity of LCTP against cysteine-reactive electrophiles and the involvement of oxidative stress in LCTP-induced cytotoxicity was investigated pre-incubating U87Mg cells with NAC, a cysteine precursor acting as ROS scavenger. NAC completely reversed the cytotoxic effects of LCTP and protected cells from morphological changes. 
AKT represents a central point of the RTK/PTEN/PI3K pathway. High levels of AKT and phospho-AKT have been detected in the majority of GBM tumor samples and cell lines, where it supports uncontrolled glioma cells growth, apoptotic blockage, and tumor invasion, thus representing an attractive pathway for GBM targeting therapy [37]. Western blot analysis displayed, in cells treated with LCTP for $30 \mathrm{~min}, 1 \mathrm{~h}, 2 \mathrm{~h}$, and $4 \mathrm{~h}$, a decrease in AKT phosphorylation, implying a strong reduction of the proliferation signaling pathway.

Finally, our study evidenced that treatment of U87Mg cells with LCTP induced-already in the first 30 min of treatment-a profound reshape of the glioblastoma cells' cytoskeleton, leading to the development of autophagic structures [38,39]. Immunofluorescence analysis revealed a profound change in $\alpha$-tubulin distribution, that appeared clearly distributed in the cytoskeletal structures of the microtubules in the control glioblastoma cells, while $\alpha$-tubulin is very concentrated in the cytoplasm after treatment with LCTP. On this side, LCTP treatment also remodeled the intermediate filament Vimentin, which appeared normally distributed in the cytoplasmic long stress fibers in control cells while accumulating near the nucleolemma, conferring a cell rounded-shaped morphology in LCTP-treated cells.

Concluding, the LCTP can be considered an excellent adjuvant substance for the treatment of glioblastoma, as it is involved in a series of mechanisms that control the growth of glioblastoma cells: autophagy, cell cycle arrest, and oxidative stress. Furthermore, the reduction of transcription factor NF- $\mathrm{BB}$ p65-a critical regulator of immune and inflammatory responses-showed a potential role of LCTP into reducing chronic inflammation. This natural substance-which potentially can pass through the BBB - used in combination with the canonical chemotherapy Temodal, opens the door to a multimodal therapy which could prove to be the most effective weapon against complex diseases, such as glioblastoma.

\section{Materials and Methods}

\subsection{Cell Culture}

The continuous human glioblastoma cell line U87Mgwas obtained from Sigma Aldrich Collection (LGCPromochem, Teddington, UK). U87Mg cells were growth in Dulbecco's Modified Eagle's Medium supplemented with 10\% fetal bovine serum, $2 \mathrm{mmol} / \mathrm{L}$-glutamine, 100IU/mL penicillin, $100 \mu \mathrm{g}$ streptomycin at $37^{\circ} \mathrm{C}, 5 \% \mathrm{CO}_{2}$, and $95 \%$ of humidity. For in vitro treatment, the pure molecule LCTP (Extrasynthase, Genay, France) and Temozolomide (Sigma Aldrich, St. Louis, MO, USA) were used.

\subsection{Estimation of Half-Maximal Inhibitory Concentration (IC50) of LCTP and TMZ in U87Mg Cells}

To estimate the IC50-values of LCTP and TMZ at 24, 48, and $72 \mathrm{~h}$, U87Mg cells were plated in 96-well plates at density of $5 \times 10^{3}$ cells/well. The IC50-values for the selected drugs were determined by using, respectively, the concentrations of 7.5, 10, 15, and $30 \mu \mathrm{M}$ for LCTP and 10, 50, 100, 150, and $200 \mu \mathrm{M}$ for TMZ. The IC50-values for LCTP and TMZ in U87Mg cells were calculated using GraphPad Prism (GraphPad Software Inc., San Diego, CA, USA).

\subsection{Proliferation Assay}

The in vitro response of U87Mg cells to LCTP were evaluated by plating human GBM cell line in 48-well plates at $1 \times 10^{4}$ cells/well in DMEM supplemented with $10 \%$ FBS, incubating them at $37^{\circ} \mathrm{C}$ in an atmosphere containing $5 \% \mathrm{CO}_{2}$. The following day, the cells were treated every $24 \mathrm{~h}$ with LCTP at concentrations of $7.5 \mu \mathrm{M}$ and $10 \mu \mathrm{M}$ for 24,48 , and $72 \mathrm{~h}$. DMSO $0.08 \%$ was used as vehicle control. At the selected time point, cell count was performed using a Burker chamber.

\subsection{Cell Viability Assay}

U87Mg cells were seeded at density of $5 \times 10^{3}$ cells in 96-well plates. The cultures were treated every $24 \mathrm{~h}$ with concentrations of LCTP $7.5 \mu \mathrm{M}$ and $10 \mu \mathrm{M}$ for 24,48 , and $72 \mathrm{~h}$, followed by MTT 
(3-(4,5-dimethylthiazol-2-yl)-2,5-diphenyltetrazolium bromide) (Sigma-Aldrich) assay. DMSO 0.08\% was used as vehicle control. Briefly, $5 \mathrm{mg} / \mathrm{mL}$ MTT was added in $100 \mu \mathrm{L}$ of cultured cells in DMEM medium. Formazan crystals were dissolved in isopropanol $/ \mathrm{HCl} 0.4 \%$ and the absorbance measured at $570 \mathrm{~nm}$ with a plate reading spectrophotometer.

LCTP-induced oxidative stress in U87Mg cells was investigated pre-treating starved cells with $\mathrm{N}$-acetylcysteine (NAC) $3 \mathrm{mM}$ for $4 \mathrm{~h}$ at $37^{\circ} \mathrm{C}$ in DMEM with FBS $10 \%$. After $4 \mathrm{~h}$, the medium was replaced and GBM cells treated with different concentrations of $\operatorname{LCTP}(7.5,10,15$, and $30 \mu \mathrm{M})$ for $24 \mathrm{~h}$. DMSO 0.2\% was used as vehicle control.

\subsection{Microscopic Observation of Cell Morphology}

U87Mg cells were seeded in 96-well plates and incubated with LCTP 7.5 $\mu \mathrm{M}$ every $24 \mathrm{~h}$ in DMEM with FBS $10 \%$ for 24,48 , and $72 \mathrm{~h}$ in the presence or absence of $\mathrm{N}$-acetylcysteine $3 \mathrm{mM}$. After treatment, morphological changes of U87Mg were observed and imaged by a phase contrast microscope (Evos, Life technologies, Carlsbad, CA, USA).

\subsection{Combined Treatment of TMZ and LCTP in Human GBM Cell Line}

The in vitro response of U87Mg cells to combined LCTPand TMZ treatment was assessed seeding GBM cells in 48-well plates (10,000 cells/well) and treating the cells every $24 \mathrm{~h}$ with TMZ $1 \mu \mathrm{M}$ alone or in combination with LCTP $7.5 \mu \mathrm{M}$ and $10 \mu \mathrm{M}$ for 24,48 , and $72 \mathrm{~h}$. At the end of each treatment, cells were counted using a Burker chamber. The combined cytotoxic effects of LCTP and TMZ were evaluated by MTT assay as above described: U87Mg cells were plated at density of $5 \times 10^{3}$ cells in 96-well plates and treated with the same combination of drugs (LCTP 7.5 $\mu \mathrm{M}$ and $10 \mu \mathrm{M}$ in combination with TMZ $1 \mu \mathrm{M}$ ) for 24,48 , and $72 \mathrm{~h}$.

\subsection{Estimation of IC50 of TMZ after Pre-Treatment with LCTP}

To test the ability of LCTP to enhance the sensitivity of U87Mg cells to TMZ, cells were plated in 96-well plates at density of $5 \times 10^{3}$ cells/well and pre-treated for $24 \mathrm{~h}$ with LCTP $7.5 \mu \mathrm{M}$ and $10 \mu \mathrm{M}$, before the estimation of IC50-values for TMZ. Cells were incubated with concentrations of TMZ 10, 50, 100, 150, and $200 \mu \mathrm{M}$ and IC50-values for TMZ at $24 \mathrm{~h}$ determined by using GraphPad Prism (GraphPad Software Inc., San Diego, CA, USA).

\subsection{Wound Healing Assay}

To evaluate cell motility, GBM cells were seeded into 6-well culture plates. When the cells reached $90 \%$ confluence, a scratch was gently made through the cell monolayer by sterile $100 \mu \mathrm{L}$ pipette tips, and the detached cells were washed away. The cell migration was observed and imaged under an Evos FL microscope (Life Technologies) for each condition (LCTP $7.5 \mu \mathrm{M}$ and $10 \mu \mathrm{M}$ ) and timepoint (T0 and T24 h).

\subsection{Clonogenic Assay}

The clonogenic assay was performed seeding $10^{3} \mathrm{U} 87 \mathrm{Mg}$ cells/well in triplicate in 6-well plates for $48 \mathrm{~h}$. Cells were treated with LCTP $7.5 \mu \mathrm{M}$ and control vehicle (0.08\% DMSO) for $24 \mathrm{~h}$ and the medium was replaced every 3 days for 14 days. The colonies were fixed with $4 \%$ paraformaldehyde solution for $5 \mathrm{~min}$, washed with PBS, and stained with crystal violet $0.05 \%$ for $30 \mathrm{~min}$.

\subsection{Western Blot Analysis of LCTP-Treated U87Mg Cells}

Protein extraction from LCTP-treated U87MG cells was performed with Triton X-100 lysis buffer (Tris-HCL 10 mM, EDTA 1 mM, NaCl 150 mM, Triton X-100 1\%, NaF 1 mM, Na $\mathrm{P}_{2} \mathrm{O}_{7} 1 \mathrm{mM}, \mathrm{Na}_{3} \mathrm{VO}_{4}$ $1 \mathrm{mM}$, and protease inhibitors $1 \times)$. Protein lysates $(15 \mu \mathrm{g})$ were resolved on a $12.5 \%$ SDS-PAGE transferred to PVDF membranes by electroblotting. The membranes were incubated for $1 \mathrm{~h}$ at room 
temperature in 5\% not-fat dry milk or bovine serum albumin (BSA) diluted in $1 \times$ Tris-buffered saline containing Tween-20 (TBST) and then incubated overnight at $4{ }^{\circ} \mathrm{C}$ with primary selected antibodies. For protein normalization, each membrane was then incubated with mouse monoclonal anti- $\beta$-actin (1:10,000, Santa Cruz Biotechnology, Santa Cruz, CA, USA) or anti-GAPDH (1:1000, Santa Cruz Biotechnology). The membranes were incubated with the specific HRP-conjugated secondary antibodies (Calbiochem). The protein bands were detected by chemiluminescence using ECL Western blotting (Amersham) and the digital signals were quantified by densitometric analysis using Image Lab Software (Bio-Rad Laboratories, Hercules, CA, USA). For cell cycle proteins CDK2, p21, and p53 analysis, the cells were plated at a density of $5 \times 10^{5}$ cells in60 mm plates in DMEM without FBS for $48 \mathrm{~h}$. After re-adding 10\% FBS, inductions were performed every $24 \mathrm{~h}$ with LCTP7.5 $\mu \mathrm{M}$ and the cells collected after 24,48 , and $72 \mathrm{~h}$ of treatment. Anti-CDK2, anti-p21 antibody (1:1000, Cell Signaling) and anti-p53 (1:1000, Roche) were used.

Changes in the phosphorylation status of ERK1/2 and AKT, in the expression level of autophagy-associated proteins p62 and LC3B and NF-кB-p65 subunit were evaluated by treating U87Mg cells with LCTP $10 \mu \mathrm{M}$ for $30 \mathrm{~min}, 1 \mathrm{~h}, 2 \mathrm{~h}$, and $4 \mathrm{~h}$. The membranes were incubated overnight with anti-pERK1/2 and anti-pAKT antibody (1:1000, Cell Signaling) in 2.5\% bovine serum albumin (BSA) in TBST. The membranes were stripped to be re-probed with non-phosphorylated forms of anti-ERK1/2 and anti-AKT (1:1000, Cell Signaling). For autophagic proteins, anti-p62 (1:1000, Cell Signaling) in $2.5 \%$ milk in TBST and LC3B (1:1000, Cell Signaling) in BSA 2.5\% in TBST were used. For NF- $\mathrm{B}$-p65 (1:1000, Santa Cruz) subunit in milk $2.5 \%$ in TBST were used.

\subsection{Western Blot of Apoptosis-Associated Proteins}

LCTP-induced apoptosis in U87Mg cells was assessed by Western blot analysis of caspases 6 and Poly (ADP-ribose) polimesare (PARP). The samples were prepared as previously reported for cell cycle proteins analysis and the PVDF membranes were incubated with caspase 6 (Cell Signaling, 1:1000), and PARP (Cell Signaling 1.100) in $2.5 \%$ milk in TBST overnight at $4{ }^{\circ} \mathrm{C}$. The incubation with secondary antibodies and detection of proteins were performed as above described.

\subsection{Immunofluorescence}

U87Mg cells $\left(5 \times 10^{3}\right)$ were plated in 8-well chamber slides in DMEM with $2 \%$ serum for 48 h. Cells were treated with LCTP $10 \mu \mathrm{M}$ in DMEM with 10\% FBS for $20 \mathrm{~min}$ and the morphological change induced by LCTP treatment assessed by immunofluorescence staining for cytoskeleton proteins, $\alpha$-tubulin, and Vimentin. In detail, at the end of treatment, U87Mg cells were fixed in $4 \%$ formalin (Diapath) for $20 \mathrm{~min}$ and permeabilized with $0.1 \%$ Triton (Invitrogen, Carlsbad, CA, USA) for $30 \mathrm{~min}$. After blocking with $10 \%$ specific serum, the cells were incubated with anti-Vimentin (prediluted; Roche diagnostic) and anti- $\alpha$-tubulin (1:200, Abcam, Cambridge, MA, USA) overnight at $4{ }^{\circ} \mathrm{C}$. After washing with $0.025 \%$ PBS-Tween-20, cells were incubated with secondary antibody anti-mouse fluorescein (1:100; Vector, Stuttgart, Germany) in 2\% serum for $1 \mathrm{~h}$ at room temperature. The slides were counterstained with DAPI Mounting Medium (Vectashield) for nuclei detection and analyzed with a fluorescence microscope at $20 \times$ and $40 \times$ magnification.

\subsection{Cell Cycle Analysis by Flow Cytometry}

U87MG human GBM cells were plated $\left(25 \times 10^{4}\right)$ in DMEM with $2 \%$ serum for $48 \mathrm{~h}$ and treated with LCTP $7.5 \mu \mathrm{M}$ every $24 \mathrm{~h}$ in DMEM with FBS 10\% for 24, 48, and $72 \mathrm{~h}$. After treatment, cells were trypsinized, washed in sample buffer (glucose $0.1 \%$ in HBSS), fixed in $70 \%$ ethanol, and stored at $4{ }^{\circ} \mathrm{C}$ overnight until the day of analysis. Before analysis, Propidium iodide $(50 \mu \mathrm{g} / \mathrm{mL})$ was added for $30 \mathrm{~min}$ at room temperature. Flow cytometry analysis of the cell cycle was performed with a Gallios instrument (Beckman Coulter, Brea, CA, USA). 


\subsection{DNA Laddering}

U87Mg cells were plated $\left(4.5 \times 10^{4}\right)$ in DMEM with $2 \%$ FBS for $48 \mathrm{~h}$ and induction performed every $24 \mathrm{~h}$ with LCTP: $7.5 \mu \mathrm{M}$ and DMSO $0.08 \%$ as vehicle control for $72 \mathrm{~h}$. At the end of treatment, the cells were collected, and the pellets were washed with phosphate buffer saline. DNA was extracted with QIAamp DNA Blood Mini kit (Qiagen, Hilden, Germany) and the DNA fragments were separated by $2 \%$ agarose gel electrophoresis and visualized by an SYBR Safe DNA Gel Stain (Invitrogen).

\subsection{Statistical Analysis}

Experiments were performed in triplicate and data were expressed as mean \pm SEM. Statistical significance was determined by Student's $t$-test, considering a $p$-value of $<0.05$ statistically significant.

Supplementary Materials: The following are available online. Figure S1(A) Representative images of wound healing assay of U87Mg cells treated with vehicle (DMSO 0.08\%) and LCTP 7.5 and $10 \mu \mathrm{M}$ at T0 and $24 \mathrm{~h}$ post-scratch (T24). Figure S2 Western blot analysis of NF-kB p65 subunit of long-term treated U87Mg cells with LCTP $7.5 \mu \mathrm{M}$ for 24,48 , and $72 \mathrm{~h}$. Data were normalized to $\beta$-actin and are expressed as fold change over control-treated cells of 3 individual determinations. * Unpaired $t$-test, $p$-value $<0.05$.

Author Contributions: R.R. performed the main experiments; M.A.O. contributed to data analysis; S.S. setting up growth curves with T.M.Z., S.C. performed M.T.T. assays, F.G. contributed to a critical revision of the manuscript; A.A. drafted this study and wrote the paper. All authors have read and agreed to the published version of the manuscript.

Funding: This research was funded by Italian Ministry of Health with Ricerca Corrente and the APC was funded by I.R.C.C.S I.N.M. Neuromed.

Acknowledgments: We are grateful to Antonio Feliciello of University of Naples Federico II and Massimo Sanchez of Istituto Superiore di Sanità (ISS).

Conflicts of Interest: The authors declare no conflict of interest.

\section{References}

1. Kleihues, P.; Louis, D.N.; Scheithauer, B.W.; Rorke, L.B.; Reifenberger, G.; Burger, P.C.; Cavenee, W.K. The WHO classification of tumors of the nervous system. J. Neuropathol. Exp. Neurol. 2002, 61, 215-225. [CrossRef] [PubMed]

2. Ciceroni, C.; Bonelli, M.; Mastrantoni, E.; Niccolini, C.; Laurenza, M.; LaRocca, L.M.; Pallini, R.; Traficante, A.; Spinsanti, P.; Ricci-Vitiani, L.; et al. Type-3 metabotropic glutamate receptors regulate chemoresistance in glioma stem cells, and their levels are inversely related to survival in patients with malignant gliomas. Cell Death Differ. 2013, 20, 396-407. [CrossRef] [PubMed]

3. De Almeida Sassi, F; Lunardi Brunetto, A.; Schwartsmann, G.; Roesler, R.; Abujamra, A.L. Glioma Revisited: From Neurogenesis and Cancer Stem Cells to the Epigenetic Regulation of the Niche. J. Oncol. 2012, 2012, 537861. [CrossRef]

4. Ohgaki, H.; Kleihues, P. Epidemiology and etiology of gliomas. Acta Neuropathol. 2005, 109, 93-108. [CrossRef] [PubMed]

5. Stupp, R.; Weber, D.C. The Role of Radio- and Chemotherapy in Glioblastoma. Oncol. Res. Treat. 2005, 28, 315-317. [CrossRef]

6. Hambardzumyan, D.; Squatrito, M.; Carbajal, E.; Holland, E.C. Glioma Formation, Cancer Stem Cells, and Akt Signaling. Stem Cell Rev. Rep. 2008, 4, 203-210. [CrossRef] [PubMed]

7. Friedman, H.S.; Kerby, T.; Calvert, H. Temozolomide and treatment of malignant glioma. Clin. Cancer Res. 2000, 6, 2585-2597.

8. Park, C.K.; Kim, J.E.; Kim, J.Y.; Song, S.W.; Kim, J.W.; Choi, S.H.; Kim, T.M.; Lee, S.H.; Kim, I.H.; Park, S. The Changes in MGMT Promoter Methylation Status in Initial and Recurrent Glioblastomas. Transl. Oncol. 2012, 5, 393-397. [CrossRef]

9. Messaoudi, K.; Clavreul, A.; Lagarce, F. Toward an effective strategy in glioblastoma treatment. Part I: Resistance mechanisms and strategies to overcome resistance of glioblastoma to temozolomide. Drug Discov. Today 2015, 20, 899-905. [CrossRef] 
10. Vengoji, R.; Macha, M.A.; Batra, S.K.; Shonka, N. Natural products: A hope for glioblastoma patients. Oncotarget 2018, 9, 22194-22219. [CrossRef]

11. Yi, G.Z.; Xiang, W.; Feng, W.Y.; Chen, Z.Y.; Li, Y.M.; Deng, S.Z.; Guo, M.L.; Zhao, L.; Sun, X.G.; He, M.Y.; et al. Identification of Key Candidate Proteins and Pathways Associated with Temozolomide Resistance in Glioblastoma Based on Subcellular Proteomics and Bioinformatical Analysis. Biomed. Res. Int. 2018, 2018, 5238760. [CrossRef] [PubMed]

12. Sestito, S.; Runfola, M.; Tonelli, M.; Chiellini, G.; Rapposelli, S. New Multitarget Approaches in the War Against Glioblastoma: A Mini-Perspective. Front. Pharmacol. 2018, 9, 874. [CrossRef] [PubMed]

13. Arcella, A.; Oliva, M.A.; Sanchez, M.; Staffieri, S.; Esposito, V.; Giangaspero, F.; Cantore, G. Effects of hispolon on glioblastoma cell growth. Environ. Toxicol. 2017, 32, 2113-2123. [CrossRef] [PubMed]

14. Arcella, A.; Oliva, M.A.; Staffieri, S.; Sanchez, M.; Madonna, M.; Riozzi, B.; Esposito, V.; Giangaspero, F.; Frati, L. Effects of aloe emodin on U87MG glioblastoma cell growth: In vitro and in vivo study. Environ. Toxicol. 2018, 33, 1160-1167. [CrossRef]

15. Kreuger, M.R.; Grootjans, S.; Biavatti, M.W.; Vandenabeele, P.; D'Herde, K. Sesquiterpene lactones as drugs with multiple targets in cancer treatment: Focus on parthenolide. Anticancer Drugs 2012, 23, 883-896.

16. Amorim, M.H.; Gil da Costa, R.M.; Lopes, C.; Bastos, M.M. Sesquiterpene lactones: Adverse health effects and toxicity mechanisms. Crit. Rev. Toxicol. 2013, 43, 559-579. [CrossRef]

17. Chadwick, M.; Trewin, H.; Gawthrop, F.; Wagstaff, C. Sesquiterpenoids lactones: Benefits to plants and people. Int. J. Mol. Sci. 2013, 14, 12780-12805. [CrossRef]

18. Ghantous, A.; Gali-Muhtasib, H.; Vuorela, H.; Saliba, N.A.; Darwiche, N. What made sesquiterpene lactones reach cancer clinical trials? Drug Discov. Today 2010, 15, 668-678. [CrossRef]

19. Babaei, G.; Aliarab, A.; Abroon, S.; Rasmi, Y.; Aziz, S.G. Application of sesquiterpene lactone: A new promising way for cancer therapy based on anticancer activity. Biomed. Pharmacother. 2018, 106, 239-246. [CrossRef]

20. Wang, J.; Yu, Z.; Wang, C.; Tian, X.; Huo, X.; Wang, Y.; Sun, C.; Feng, L.; Ma, J.; Zhang, B.; et al. Dehydrocostus lactone, a natural sesquiterpene lactone, suppresses the biological characteristics of glioma, through inhibition of the NF-kappaB/COX-2 signaling pathway by targeting IKKbeta. Am. J. Cancer Res. 2017, 7, 1270-1284.

21. Wang, X.; Yu, Z.; Wang, C.; Cheng, W.; Tian, X.; Huo, X.; Wang, Y.; Sun, C.; Feng, L.; Xing, J.; et al. Alantolactone, a natural sesquiterpene lactone, has potent antitumor activity against glioblastoma by targeting IKKbeta kinase activity and interrupting NF-kappaB/COX-2-mediated signaling cascades. J. Exp. Clin. Cancer Res. 2017, 36, 93. [CrossRef] [PubMed]

22. Youn, U.J.; Miklóssy, G.; Chai, X.; Wongwiwatthananukit, S.; Toyama, O.; Songsak, T.; Turkson, J.; Chang, L.C. Bioactive sesquiterpene lactones and other compounds isolated from Vernonia cinerea. Fitoterapia 2014, 93, 194-200. [CrossRef] [PubMed]

23. Zhang, X.; Lan, D.; Ning, S.; Ruan, L. Anticancer action of lactucopicrin in SKMEL-5 human skin cancer cells is mediated via apoptosis induction, G2/M cell cycle arrest and downregulation of $\mathrm{m}=\mathrm{TOR} / \mathrm{PI} 3 \mathrm{~K} / \mathrm{AKT}$ signalling pathway. J. BUON 2018, 23, 224-228. [PubMed]

24. Meng, Q.; Tang, B.; Qiu, B. Growth inhibition of Saos-2 osteosarcoma cells by lactucopicrin is mediated via inhibition of cell migration and invasion, sub-G1 cell cycle disruption, apoptosis induction and Raf signalling pathway. J. BUON 2019, 24, 2136-2140.

25. Wierzbicki, M.; Sawosz, E.; Strojny, B.; Jaworski, S.; Grodzik, M.; Chwalibog, A. NF-kappaB-related decrease of glioma angiogenic potential by graphite nanoparticles and graphene oxide nanoplatelets. Sci. Rep. 2018, 8, 14733. [CrossRef]

26. Stupp, R.; Hegi, M.E.; Mason, W.P.; van den Bent, M.J.; Taphoorn, M.J.; Janzer, R.C.; Ludwin, S.K.; Allgeier, A.; Fisher, B.; Belanger, K.; et al. Effects of radiotherapy with concomitant and adjuvant temozolomide versus radiotherapy alone on survival in glioblastoma in a randomised phase III study: 5-year analysis of the EORTC-NCIC trial. Lancet Oncol. 2009, 10, 459-466. [CrossRef]

27. Yin, S.Y.; Wei, W.C.; Jian, F.Y.; Yang, N.S. Therapeutic applications of herbal medicines for cancer patients. Evid. Based Complement. Altern. Med. 2013, 2013, 302426. [CrossRef]

28. Liu, C.A.; Chang, C.Y.; Hsueh, K.W.; Su, H.L.; Chiou, T.W.; Lin, S.Z.; Harn, H.J. Migration/Invasion of Malignant Gliomas and Implications for Therapeutic Treatment. Int. J. Mol. Sci. 2018, 19, 1115. [CrossRef] 
29. Li, C.; Han, X. Anthecotulide Sesquiterpene Lactone Exhibits Selective Anticancer Effects in Human Malignant Melanoma Cells by Activating Apoptotic and Autophagic Pathways, S-Phase Cell Cycle Arrest, Caspase Activation, and Inhibition of NF-kappaBSignalling Pathway. Med. Sci. Monit. 2019, 25, 2852-2858. [CrossRef]

30. Deng, D.; Luo, K.; Liu, H.; Nie, X.; Xue, L.; Wang, R.; Xu, Y.; Cui, J.; Shao, N.; Zhi, F. p62 acts as an oncogene and is targeted by miR-124-3p in glioma. Cancer Cell Int. 2019, 19, 280. [CrossRef]

31. Xu, H.; Sun, L.; Zheng, Y.; Yu, S.; Ou-Yang, J.; Han, H.; Dai, X.; Yu, X.; Li, M.; Lan, Q. GBP3 promotes glioma cell proliferation via SQSTM1/p62-ERK1/2 axis. Biochem. Biophys. Res. Commun. 2018, 495, 446-453. [CrossRef] [PubMed]

32. Friedmann-Morvinski, D.; Narasimamurthy, R.; Xia, Y.; Myskiw, C.; Soda, Y.; Verma, I.M. Targeting NF-kappaB in glioblastoma: A therapeutic approach. Sci. Adv. 2016, 2, e1501292. [CrossRef] [PubMed]

33. Hehner, S.P.; Heinrich, M.; Bork, P.M.; Vogt, M.; Ratter, F.; Lehmann, V.; Schulze-Osthoff, K.; Droge, W.; Schmitz, M.L. Sesquiterpene lactones specifically inhibit activation of NF-kappa B by preventing the degradation of I kappa B-alpha and I kappa B-beta. J. Biol. Chem. 1998, 273, 1288-1297. [CrossRef] [PubMed]

34. Pajak, B.; Gajkowska, B.; Orzechowski, A. Molecular basis of parthenolide-dependent proapoptotic activity in cancer cells. Folia Histochem. Cytobiol. 2008, 46, 129-135. [CrossRef] [PubMed]

35. Efferth, T. Willmar Schwabe Award 2006: Antiplasmodial and antitumor activity of artemisinin-From bench to bedside. Planta Med. 2007, 73, 299-309. [CrossRef]

36. Su, J.; Liu, F.; Xia, M.; Xu, Y.; Li, X.; Kang, J.; Li, Y.; Sun, L. p62 participates in the inhibition of NF-kappaB signaling and apoptosis induced by sulfasalazine in human glioma U251 cells. Oncol. Rep. 2015, 34, $235-243$. [CrossRef]

37. McDowell, K.A.; Riggins, G.J.; Gallia, G.L. Targeting the AKT pathway in glioblastoma. Curr. Pharm. Des. 2011, 17, 2411-2420. [CrossRef]

38. Izdebska, M.; Halas-Wisniewska, M.; Zielinska, W.; Klimaszewska-Wisniewska, A.; Grzanka, D.; Gagat, M. Lidocaine induces protective autophagy in rat C6 glioma cell line. Int. J. Oncol. 2018, 54, 1099-1111. [CrossRef]

39. Li, S.S.; Xu, L.Z.; Zhou, W.; Yao, S.; Wang, C.L.; Xia, J.L.; Wang, H.F.; Kamran, M.; Xue, X.Y.; Dong, L.; et al. p62/SQSTM1 interacts with vimentin to enhance breast cancer metastasis. Carcinogenesis 2017, 38, 1092-1103. [CrossRef]

Publisher's Note: MDPI stays neutral with regard to jurisdictional claims in published maps and institutional affiliations.

(C) 2020 by the authors. Licensee MDPI, Basel, Switzerland. This article is an open access article distributed under the terms and conditions of the Creative Commons Attribution (CC BY) license (http://creativecommons.org/licenses/by/4.0/). 